\title{
SISTEM INFORMASI PENGENDALIAN BAHAN BAKU MENGGUNAKAN METODE MATERIAL REQUIREMENT PLANNING PADA PD. SAMIJAYA SUKABUMI BERBASIS WEB
}

\author{
Riva Lady Rishmaya \\ PD. Samijaya Sukabumi \\ riva.lady1@gmail.com \\ Kp.babakanpeundeuy rt.03/03, Des.bojongkokosan, Kec.parungkuda, Kab.sukabumi
}

*Korespondensi : e-mail: riva.lady1@gmail.com

\begin{abstract}
ABSTRAK
Sebuah perusahaan sering mengalami kesulitan dalam mengendalikan bahan baku, termasuk terlalu banyak atau terlalu sedikit pasokan. Kajian ini bertujuan untuk mengendalikan atau mengetahui jumlah bahan baku yang harus disediakan, sedangkan perumusan masalah studi ini adalah bagaimana menerapkan metode perencanaan kebutuhan material untuk mengontrol jumlah stok bahan baku, bagaimana desain sistem dibuat, dan bagaimana antarmuka sistem dibuat. Teori dasar yang digunakan adalah sistem informasi manajemen, manajemen rantai suplai dan perencanaan kebutuhan material. Dimana teori ini berhubungan dengan penelitian yang dilakukan. Sampel penelitian dilakukan dengan wawancara langsung dengan pemilik perusahaan.
\end{abstract}

Kata kunci : Supply Chain Management, Sistem Informasi Manajemen, Perencanaan Kebutuhan Material.

ABSTRACT

A Company often has difficulties in controlling raw materials, including too much or too little supply. This study aims to control or know the amount of raw material that must be provided, while the formulation of the problem of this study is how to apply the Material Requirement Planning method to control the amount of raw material stock, how the system design is made, and how the system interface is made. The basic theory used is management information systems, supply chain management and Material Requirement Planning. Where the theory is related to research conducted. The research sample was carried out by direct interviews with company owners.

Keywords : Supply Chain Management, management information systems, Material Requirement Planning.

\section{PENDAHULUAN}

PD. Samijaya bergerak dibidang perkayuan khususnya dalam pembuatan kayu peti untuk uang. Perusahaan yang sedang berkembang dituntut untuk melakukan kegiatan usahanya dengan baik. Oleh karenanya diperlukannya suatu pengelolaan yang terkoordinasi secara tepat yang bertujuan untuk mempermudah proses kegiatan untuk mencapai tujuan perusahaan. Ini berarti diperlukan penyusunan kebijakan dan strategi perusahaan. Karena seperti diketahui, perkembangan dunia teknologi dan informasi menuntut semuanya serba cepat dan tepat. Masalah yang di temukan dilapangan yaitu kesulitan dalam mengatur jumlah bahan baku yang harus di sediakan agar sesuai dengan pesanan, bahan baku sering mengalami penjamuran atau pembusukan akibat stok bahan baku yang terlalu over atau berlebihan dikarena kan perusahaan masih belum memiliki sistem untuk mengetahui persediaan bahan baku dan hanya memperkirakan dengan manual saja. Penelitian ini digunakan metode Material Requirement Planning (MRP) yang digunakan untuk menentukan bahan-bahan atau komponen-komponen apa yang harus di buat atau di beli, berapa jumlah yang dibutuhkan dan kapan dibutuhkan. Selain itu untuk mengendalikan pesanan-pesanan dalam produksi dan pembelian untuk mengatur aliran bahan baku dan persediaan dalam proses, sehingga sesuai dengan jadwal produksi untuk produk akhir [1]. Penelitian ini memberikan solusi dalam toleransi proses pengendalian bahan baku sehingga penumpukan menjadi kecil bahkan tidak ada. Manfaat yang didapatkan yaitu perusahan dapat dengan mudah mengetahui jumlah bahan baku yang harus disediakan dengan cara menginput jumlah pesanan, juga dapat menyimpan history jumlah pemesanan barang. 
JURSISTEKNI (Jurnal Sistem Informasi dan Teknologi Informasi) Volume 2, No.2, Mei 2020: Hal 14- 24 ISSN. P: 2715-1875, E: 2715-1883

\subsection{Penelitian Terkait}

\section{TINJAUAN PUSTAKA}

Neneng Winarsih, et. al (2013) dengan judul "Penerapan Software Pom-Qm dalam Pengadaan Material Proyek dengan Teknik PPB" mengemukakan bahwa Metode Part Period Balancing sangat membantu dalam mempermudah menentukan persediaan kebutuhan material dalam suatu proyek konstruksi. Penggunaan software POM-QM v.3.0 dapat mempermudah dalam melakukan perhitungan persediaan material dan biaya persediaan material, sehingga hasil yang diperoleh dapat lebih akurat [2].

Fachrurrozi, et. al (2014) dengan judul "Lot Sizing Material Requirement Planning Pada Produk Tipe Wall Mounting Di Industri Box Panel" mengemukakan bahwa Material Requirement Planning (MRP) yang telah dilakukan, metode LFL memperoleh total biaya pengadaan material, biaya pesan dan biaya simpan paling rendah yaitu Rp 562.787 .335 bila dibandingkan dengan metode Foq, Eoq, Poq. Sedangkan yang mempunyai biaya pengadaan material sangat tinggi ditunjukan oleh teknik perhitungan dengan metode Poq dengan total biaya Rp.792.918.458 [3].

Muhammad Arief, et. al (2017) dengan judul "Analisis Perencanaan Persediaan Batubara Fx dengan Metode Material Requirement Planning" mengemukakan bahwa Berdasarkan analisis data yang telah dilakukan, diperoleh hasil yang menunjukkan bahwa metode simple average merupakan metode terpilih berdasarkan nilai kesalahan yang paling kecil dibandingkan dengan metode yang lain. Metode Fixed Period Requirement merupakan metode terbaik untuk perencanaan kebutuhan bahan dilihat dari minimum biaya total yang dikeluarkan [4].

Asvin Wahyuni, et. al (2015) dengan judul "Perencanaan Persediaan Bahan Baku dengan Menggunakan Metode Material Requirement Planning (MRP) Produk Kacang Shanghai Pada Perusahaan Gangsar Ngunut-Tulungagung" mengemukakan bahwa MRP menjadikan sistem penyediaan bahan baku menjadi lebih mudah karena telah terjadwal dengan baik yang dapat menghindarkan stock out, dan over stock sehingga tidak akan menghambat proses produksi, sehingga metode MRP lebih efektif dari pada metode yang sedang berjalan [5].

Retno Vella (2017) dengan judul "Aplikasi Pengendalian Persediaan Bahan Baku Berbasis Web Menggunakan Metode Material Requirement Planning (MRP)" mengemukakan bahwa Aplikasi Ini mempunyai fungsionalitas membuat daftar penjualan dari hasil pemesanan pelanggan, menghasilkan Bill of Material (BOM), membuat Material Planning Schedule (MPS) berdasarkan periode pesanan pelanggan, dan menghasilkan table Material Requirement Planning (MRP), membuat transaksi dalam bentuk jurnal, buku besar dan neraca saldo, Fungsionalitas berjalan 100\% setelah diujikan dengan blackbox testing dan perbandingan pengujian manual berhasil diimplementasikan sesuai dengan aplikasi. Aplikasi dapat membantu perusahaan menghitung persediaan bahan baku sesuai dengan jumlah, kebutuhan dan waktu yang dibutuhkan [6].

\subsection{Analisis Kesenjangan}

Secara umum gap analisys dapat didefinisikan sebagai suatu metode atau alat yang digunakan untuk mengetahui tingkat kinerja suatu perusahaan atau institusi. Dalam kondisi umum, kinerja suatu perusahaan atau institusi dapat tercermin dalam sistem operasional maupun strategi yang digunakan oleh institusi tersebut. Secara singkat, gap analisys bermanfaat untuk:

1. Menilai seberapa besar kesenjangan antara kinerja aktual dengan suatu standar kerja yang diharapkan

2. Mengetahui peningkatan kinera yang diperlukan untuk menutup kesenjangan tersebut, dan

3. Menjadi salah satu dasar pengambilan keputusan terkait prioritas dan biaya yang dibutuhkan untuk memenuhi standar pelayanan yang telah ditetapkan. [7].

Pada penelitian ini dilakukan analysis gap dari penelitian sebelumnya yang memiliki kekurangan karena tidak ada sistem yang dibuat dalam implementasinya serta dari kondisi di lokasi penelitian 
JURSISTEKNI (Jurnal Sistem Informasi dan Teknologi Informasi) Volume 2, No.2, Mei 2020: Hal 14- 24 ISSN. P: 2715-1875, E: 2715-1883

yang menuntut ketelitian, keakuratan dalam ketersedian barang agar dapat meningkatkan keuntungan perusahaan.

\subsection{Kerangka berfikir}

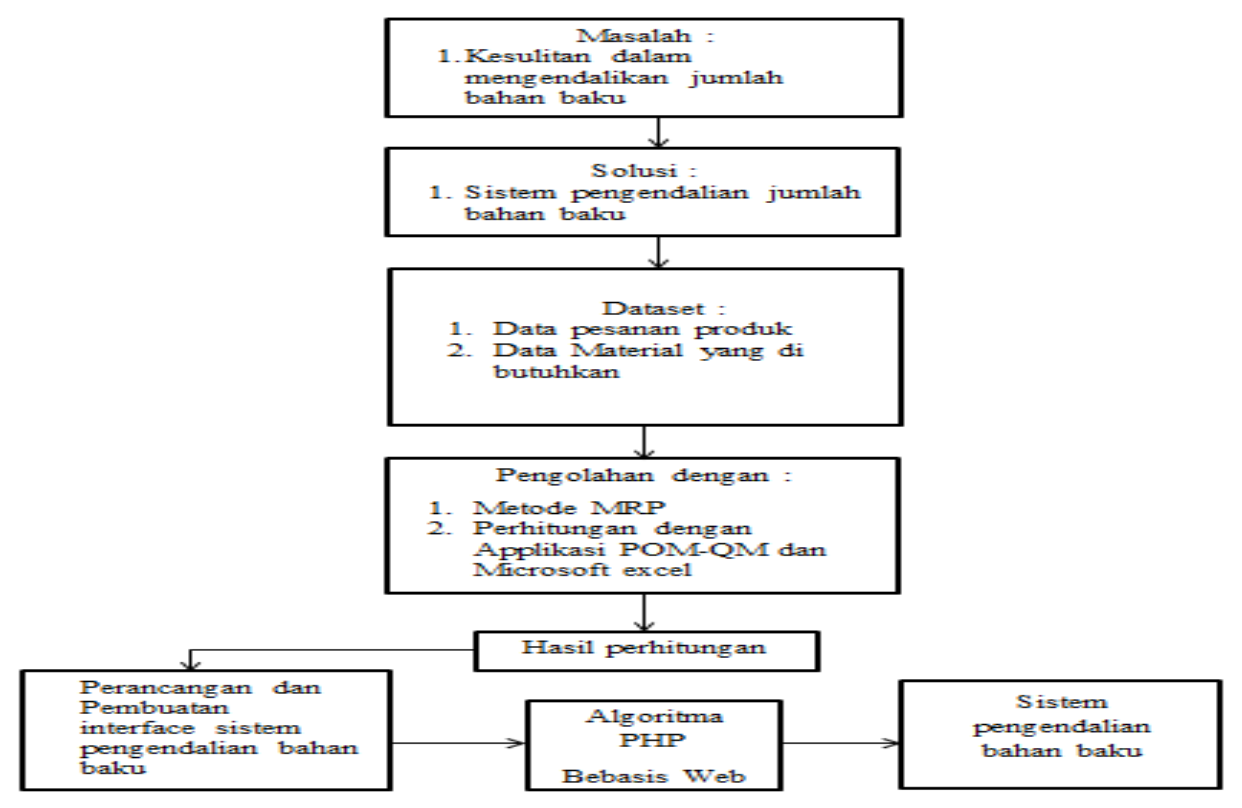

Gambar 1. Kerangka berfikir yang dirancang

\section{METODE PENELITIAN}

Dalam penelitian ini menggunakan data kuantitatif dan kuantitatif. Metode pengumpulan data pada penelitian ini yaitu dengan metode wawancara secara langsung mengajukan beberapa pertanyaan kepada pemilik perusahaan. Juga dilakukan metode observasi yaitu melihat secara langsung keadaan dan situasi yang sebenarnya terjadi pada perusahaan PD.Samijaya.

Data yang digunakan dalam penelitian ini adalah data primer berupa data perusahaan tahun 2016. Data primer ini merupakan data yang diperoleh secara langsung dari pihak perusahaan.

Tabel 1. Pesanan kayu peti Januari 2016

\begin{tabular}{|c|c|c|c|c|c|c|c|}
\hline \multirow[t]{2}{*}{ No } & \multirow{2}{*}{$\begin{array}{c}\text { Tanggal } \\
\text { Pemesanan }\end{array}$} & \multirow[t]{2}{*}{ Pemesan } & \multirow{2}{*}{$\begin{array}{l}\text { Jumlah } \\
\text { Pesanan }\end{array}$} & \multicolumn{4}{|c|}{ Target penyelesaian produk } \\
\hline & & & & P1 & $\mathbf{P 2}$ & $\mathbf{P 3}$ & $\mathbf{P 4}$ \\
\hline 1 & $02 / 01 / 2016$ & peruri & 7000 & 2000 & 2000 & 2000 & 1000 \\
\hline 2 & $04 / 01 / 2016$ & beacukai & 5000 & 1000 & 2000 & 1000 & 1000 \\
\hline 3 & $05 / 02 / 2016$ & beacukai & 6000 & 2000 & 2000 & 1000 & 1000 \\
\hline 4 & $07 / 02 / 2016$ & peruri & 5000 & 1000 & 2000 & 1000 & 1000 \\
\hline 5 & $04 / 03 / 2016$ & beacukai & 7000 & 2000 & 2000 & 2000 & 1000 \\
\hline 6 & $06 / 03 / 2016$ & peruri & 7000 & 2000 & 2000 & 2000 & 1000 \\
\hline 7 & $02 / 04 / 2016$ & beacukai & 8000 & 2000 & 2000 & 2000 & 2000 \\
\hline 8 & $04 / 04 / 2016$ & peruri & 6000 & 2000 & 2000 & 1000 & 1000 \\
\hline 9 & $03 / 05 / 2016$ & peruri & 9000 & 2000 & 3000 & 2000 & 2000 \\
\hline 10 & $07 / 05 / 2016$ & beacukai & 9500 & 3000 & 2000 & 2500 & 2000 \\
\hline 11 & $01 / 06 / 2016$ & beacukai & 10000 & 2000 & 3000 & 3000 & 2000 \\
\hline 12 & $04 / 06 / 2016$ & peruri & 7000 & 2000 & 2000 & 2000 & 1000 \\
\hline 13 & $29 / 06 / 2016$ & $\begin{array}{l}\text { PT.Tri } \\
\text { usaha }\end{array}$ & 5000 & 1000 & 2000 & 1000 & 1000 \\
\hline 14 & $02 / 07 / 2016$ & beacukai & 9500 & 2000 & 3000 & 2000 & 2500 \\
\hline 15 & $06 / 07 / 2016$ & peruri & 8000 & 2000 & 3000 & 2000 & 1000 \\
\hline 16 & $03 / 08 / 2016$ & peruri & 9500 & 3000 & 2000 & 3000 & 1500 \\
\hline 17 & $05 / 08 / 2016$ & beacukai & 9500 & 2000 & 3000 & 2000 & 2500 \\
\hline
\end{tabular}

Metode Analisa yang digunakan penelitian ini adalah Analisa kuantitatif dengan pengolahan data menggunakan Material Requirements Planning (MRP). Perancangan atau langkah-langkah penelitian ini yaitu Menetukan rumusan masalah, Menetukan metode penelitian dan penerapan Supply chain management, memahami dan mempelajari metode Material Requirements Planning 
(MRP), perhitungan hasil menggunakan Aplikasi $P O M-Q M$, perancangan dan pembangunan Aplikasi berbasis $W E B$, pembangunan dan perancangan menggunakan $P H P$ dan Implementasi aplikasi yang dilakukan adalah menentukan jumlah atau banyak nya bahan baku yang harus di persiapkan.

Penelitian di lakukan di PD. Samijaya yang terletak di daerah sukabumi, perusahaan ini bergerak dibidang pengelolaan kayu, khususnya dalam pembuatan peti, yang jumlah produksinya berdasarkan order dari konsumen. Untuk peti sebagian besar order datang dari perum peruri (percetakan uang) untuk peti uang kertas maupun logam. Jenis kayu yang biasa digunakan dalam produksi adalah kayu albasia. Bertepatan di Jl.Raya Parungkuda, Sukabumi, Jawa barat.

Metode yang di gunakan pada penelitian ini adalah metode Material Requirement Planning (MRP) untuk menghitung jumlah persediaan bahan baku secara efisien yang di telah di analisis sesuai dengan permasalahan yang akan di selesaikan, pada metode Material Requirement Planning ini memiliki beberapa tahap yang harus di uraikan yaitu sebagai berikut :

1. Master Production Schedule atau Jadwal Produksi Induk adalah suatu perencanaan yang terdiri dari tahapan waktu dan jumlah produk jadi yang akan diproduksi oleh sebuah perusahaan manufakturing. MPS ini pada umumnya berdasarkan order (pesanan) pelanggan dan perkiraan order (Forecast) yang dibuat oleh perusahaan sebelum dimulainya sistem MRP. Seperti yang disebutkan sebelumnya, MRP adalah terjemahaan dari MPS (Jadwal Produksi Induk) untuk Material.

2. Inventory Status File ini berkaitan dengan hasil perhitungan persediaan dan kebutuhan bersih untuk setiap periode perencanaan. Setiap inventory atau persediaan harus memberikan informasi status yang jelas dan terbaru mengenai jumlah persediaan yang ada saat ini, jadwal penerimaan material ataupun rencana pembelian yang akan diserahkan ke pemasok.

3. Bill of Materials (BOM) adalah sebuah daftar yang berisikan jumlah masing-masing bahan baku, bahan pendukung dan sub-assy (semi produk) yang dibutuhkan untuk membuat suatu produk jadi [8].

4. Pom-qm adalah aplikasi pada tahap perhitungan untuk hasil dari Material Requirement Planning $(M R P)$ menggunakan Applikasi POM-QM.

Berikut adalah perhitungan atau rumus yang di gunakan untuk menghitung hasil dari MRP (Material Requirement Planning) ini :

$\mathrm{X}=$ Produk Jadi (Peti Kayu)

$\mathrm{BB}=$ Bahan Baku

Rumusnya :

$\mathrm{X}$ : Total pesanan - stok gudang

BB : Total pesanan - Stok jadi x Jumlah satuan

\subsection{Perancangan sistem}

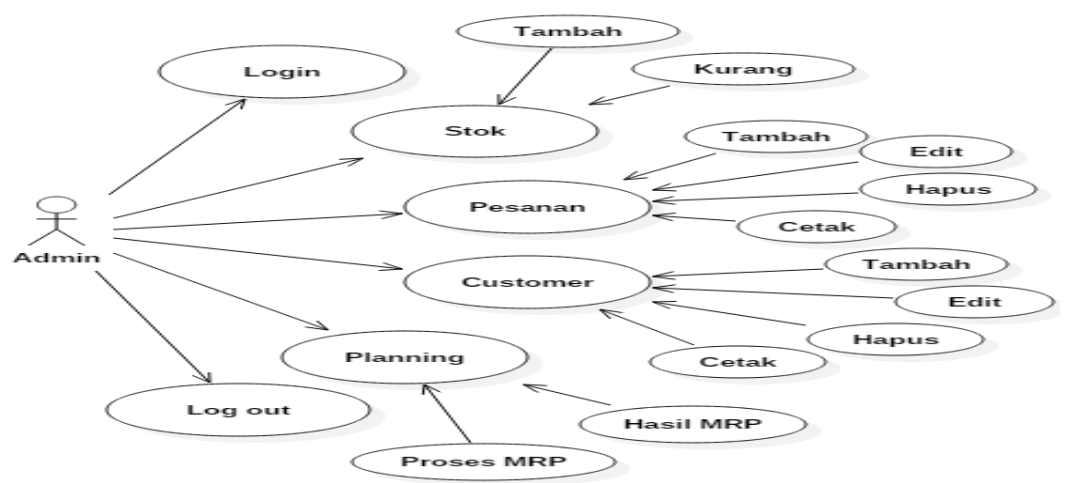

Gambar 2. Usecase diagram yang dirancang 
Pada gambar 2 diatas perancangan yang di buat pada bagian usecase nya yaitu memiliki satu aktor atau yang dinamakan admin di mana admin tersebut bisa melakukan login logout dan menginput data yang terdiri dari data pesanan, customer, stok dan planning, pada bagian form planning admin bisa langsung melihat hasil perhitungan yang sudah admin input pada form yang sudah di jelaskan tadi. Pada form pesanan dan juga form customer admin memiliki atribut diantaranya tambah, edit, hapus, dan juga cetak, sedangkan pada form stok yaitu memiliki atribut tambah dan kurang.

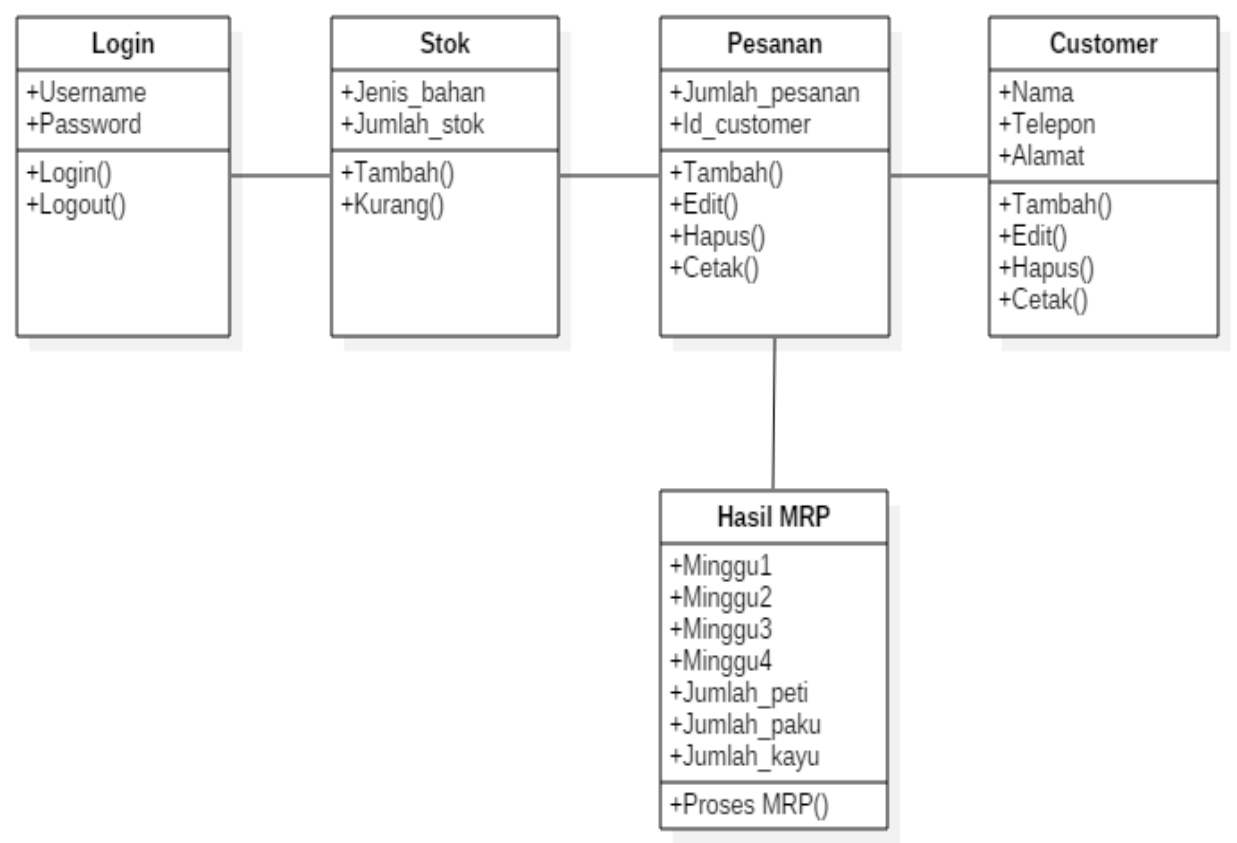

Gambar 3. Class diagram

Class diagram 3 diatas aplikasi yang di buat memiliki 5 class diantaranya login, stok, pesanan, customer dan hasil perhitungan nya dengan MRP (Material Requirement Planning). Pada class login memiliki inputan username dan password dengan atribut login dan logout, pada class stok memiliki inputan jenis bahan dan jumlah stok dengan atribut tambah dan kurang, pesanan memiliki inputan jumlah pesanan dan id customer dengan atribut tambah, edit, hapus dan cetak, untuk class customer memiliki inputan nama, telepon dan alamat dengan attribut yang di miliki sama dengan atribut dari class pesanan, dan yang terakhir yaitu class planning dimana pada form tersebut adalah hasil perhitungan dari inputan diantaranya form stok, pesanan, dan customer.

\subsection{Uji Aplikasi}

Untuk memastikan bahwa perangkat lunak yang dibuat memiliki standar minimal kualitas, maka salah satu metoda untuk pengukuran kualitas perangkat lunak secara kuantitatif adalah metoda SQA (Software Quality Assurance). 
JURSISTEKNI (Jurnal Sistem Informasi dan Teknologi Informasi) Volume 2, No.2, Mei 2020: Hal 14- 24 ISSN. P: 2715-1875, E: 2715-1883

Tabel 2. Metric of Software Quality Assurance (SQA)

\begin{tabular}{|r|l|l|c|}
\hline No & \multicolumn{1}{|c|}{ Metrik } & Deskripsi & Bobot \\
\hline 1 & Auditability & Memenuhi standard atau tidak & 0.125 \\
\hline 2 & Accuracy & Keakuratan komputasi & 0.125 \\
\hline 3 & Completeness & Kelengkapan & 0.125 \\
\hline 4 & Error Tolemce & Toleransi terhadap kesalahan & 0.125 \\
\hline 5 & Expandability & Pengembangan perangkat lunak & 0.125 \\
\hline 6 & Operability & Kemudahan untuk dioperasikan & 0.125 \\
\hline 7 & Simplicity & Kemudahan untuk di pahami & 0.125 \\
\hline 8 & Training & $\begin{array}{l}\text { Kemudahan pembelajaran } \\
\text { fasilitas Help }\end{array}$ & 0.125 \\
\hline
\end{tabular}

\section{HASIL DAN PEMBAHASAN}

Pada gambar 4 dibawah menunjukan tingkat pemesanan yang paling banyak yaitu pada bulan juni 2016 bila di lihat dari data yang di dapatkan pada bulan tersebut pemesan ada 3 perusahaan yang memesan, sedangkan pada bulan lain pemesan terdapat dua perusahaan, selain itu pada awal tahun banyak nya pemesan berada di tingkat 10000 sampai dengan 15000 dan pada akhir tahun pemesan meningkat sampai dengan 25000.

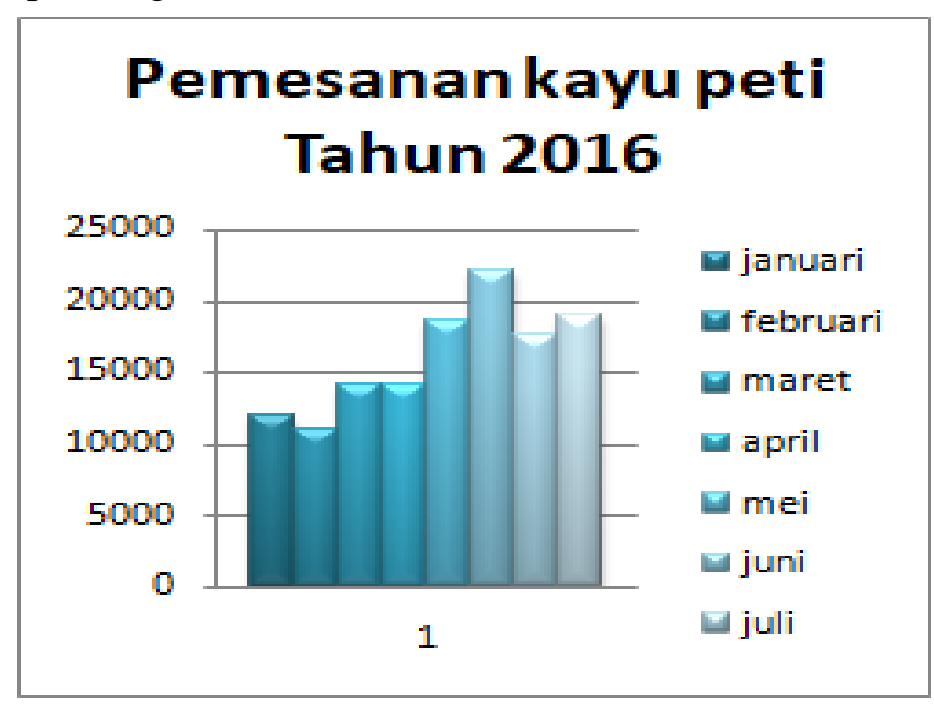

Gambar 4. Grafik pemesanan kayu peti 
JURSISTEKNI (Jurnal Sistem Informasi dan Teknologi Informasi) Volume 2, No.2, Mei 2020: Hal 14- 24 ISSN. P: 2715-1875, E: 2715-1883

Pada tabel 3 dibawah ini menunjukan hasil dari perhitungan Material Requirement Planning menggunakan aplikasi $P O M-Q M$. Dimana hasil tersebut otomatis keluar setelah menginput jumlah pesanan dan stok yang ada di gudang.

Tabel 3. Hasil Perhitungan MRP dengan Applikasi POM-QM.

\begin{tabular}{|c|c|c|c|c|c|}
\hline \multicolumn{6}{|c|}{1000 Solution } \\
\hline $\begin{array}{l}\text { Item name } \\
\text { (low level) }\end{array}$ & $\begin{array}{l}\text { Pd } 0 \\
\text { and } \\
\text { before }\end{array}$ & pd1 & pd2 & pd3 & $\mathrm{pd} 4$ \\
\hline Gross REQ. & & 4000 & 3000 & 3000 & 2000 \\
\hline ON HAND & 540 & 540 & 8540 & 5540 & 2540 \\
\hline \multicolumn{6}{|l|}{ SchdREC. } \\
\hline NET REQ & & 3460 & & & \\
\hline PlanREC & & 12000 & & & \\
\hline \multicolumn{6}{|l|}{ ORD REL. } \\
\hline \multicolumn{6}{|l|}{ Paku ( 1) } \\
\hline \multicolumn{6}{|l|}{ Gross REQ. } \\
\hline ON HAND & 28500 & 28500 & 156500 & 261500 & 366500 \\
\hline SchdREC. & & 128000 & 105000 & 105000 & 64000 \\
\hline \multicolumn{6}{|l|}{ NET REQ } \\
\hline \multicolumn{6}{|l|}{ PlanREC } \\
\hline \multicolumn{6}{|l|}{ ORD REL. } \\
\hline \multicolumn{6}{|c|}{ Log kayu (1) } \\
\hline \multicolumn{6}{|l|}{ Gross REQ. } \\
\hline ON HAND & 270 & 270 & 4270 & 7270 & 10270 \\
\hline
\end{tabular}

\subsection{Interface sistem}

$\checkmark$ Selanat Datang Rova!

Dashboard

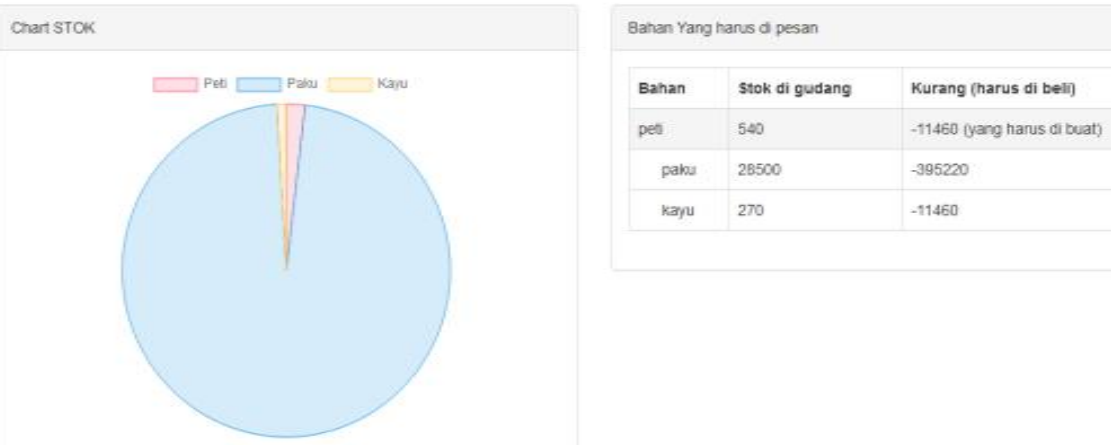

Gambar 5. Tampilan dashboard 
JURSISTEKNI (Jurnal Sistem Informasi dan Teknologi Informasi) Volume 2, No.2, Mei 2020: Hal 14- 24 ISSN. P: 2715-1875, E: 2715-1883

Dashboard Stok Pesanan Costumer Planning

\section{Data Stok}

\begin{tabular}{|lll|l|}
\hline Jenis Bahan & Stok & \multicolumn{2}{l|}{ Aksi } \\
\hline peti & 540 & + Tambah & - Kurangi \\
\hline paku & 28500 & + Tambah & - Kurangi \\
\hline kayu & 270 & + Tambah & -Kurangi \\
\hline
\end{tabular}

Gambar 6. Tampilan data stok

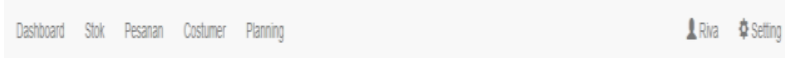

Pesanan-Tanbah

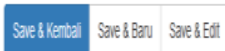

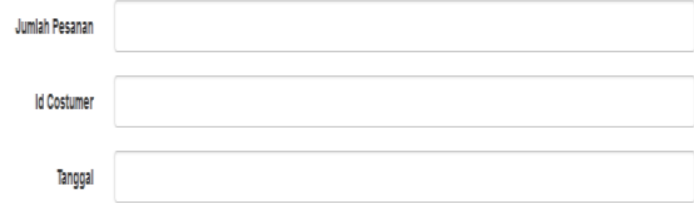

Gambar 7. Tampilan input data pesanan

\section{Planing}

\begin{tabular}{|c|c|c|c|}
\hline \multicolumn{2}{|c|}{ TOTAL STOKDI GUDANG } & \multicolumn{2}{|c|}{ TOTAL PESANAN } \\
\hline Jenis Bahan & Stok & Pemesan & Jumlah Pesan \\
\hline peti & 540 & Peruri & 7000 \\
\hline paku & 28500 & Beacukai & 5000 \\
\hline kayu & 270 & TOTAL & 12000 \\
\hline
\end{tabular}

Gambar 8. Tampilan Planning 


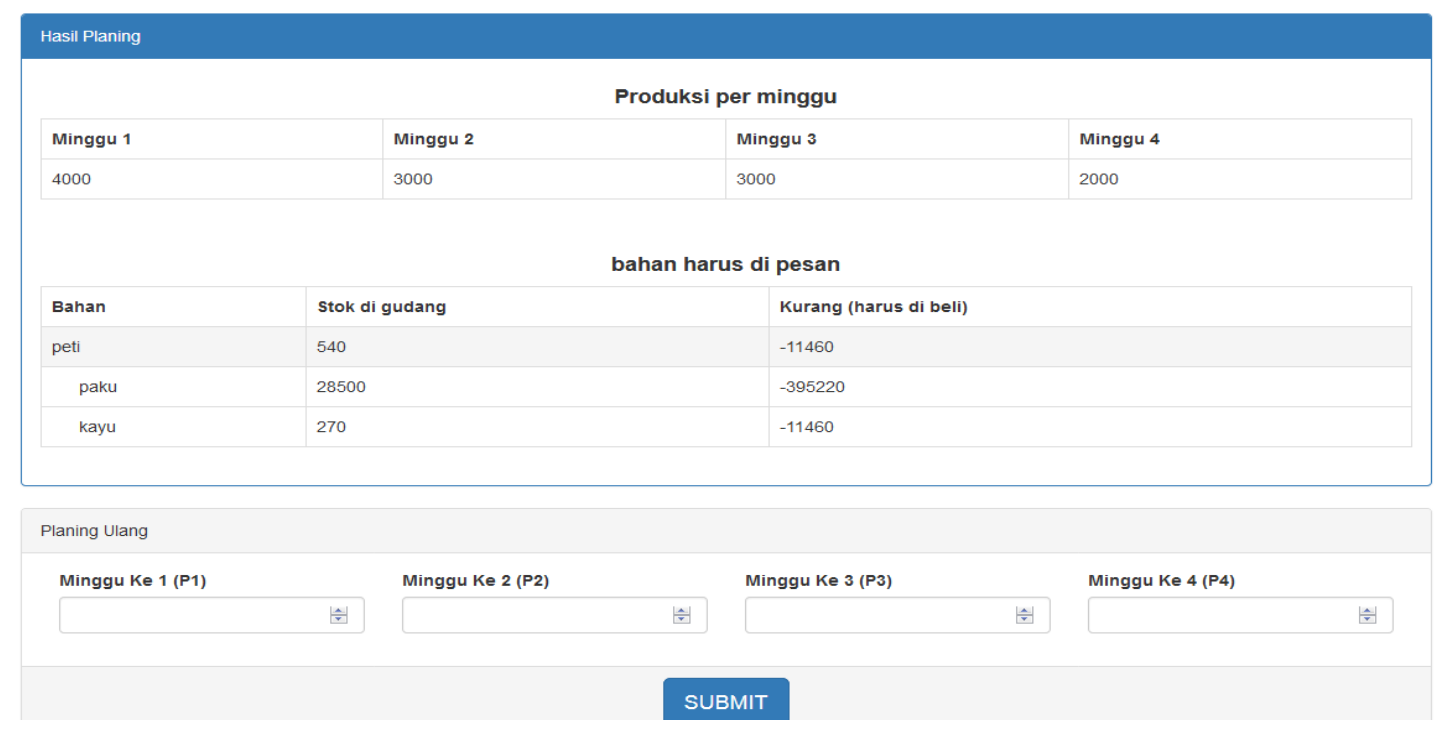

Gambar 9. Tampilan hasil

\subsection{Hasil uji Software Quality Asurance (SQA)}

Proses yang dilakukan untuk menilai apakah yang dirancang telah sesuai dengan apa yang diharapkan, pada penelitian ini menggunakan uji aplikasi dengan $S Q A$.

Tabel 4. Hasil uji Software Quality Asurance (SQA)

\begin{tabular}{|c|c|c|c|c|c|c|c|c|c|}
\hline \multirow{2}{*}{ Audience } & \multicolumn{8}{|c|}{ Skor Metrik } & \multirow{2}{*}{ Skor } \\
\hline & 1 & 2 & 3 & 4 & 5 & 6 & 7 & 8 & \\
\hline$\# 1$ & 79 & 80 & 80 & 82 & 80 & 83 & 83 & 78 & 80.625 \\
\hline$\# 2$ & 77 & 82 & 80 & 87 & 81 & 90 & 85 & 82 & 84 \\
\hline$\# 3$ & 79 & 80 & 81 & 80 & 89 & 95 & 87 & 85 & 84.5 \\
\hline$\# 4$ & 73 & 75 & 81 & 82 & 97 & 90 & 80 & 84 & 82.75 \\
\hline$\# 5$ & 79 & 75 & 82 & 81 & 88 & 92 & 80 & 88 & 83 \\
\hline \multicolumn{9}{|c|}{ Rata-Rata } & 82,775 \\
\hline
\end{tabular}

Pada tabel 4 diatas merupakan hasil angket yang dilakukan pada 5 orang pengamat yang berperan sebagi user dan diambil secara acak.

Skor $=\langle 77\rangle * 0.125+\langle 78,4\rangle * 0.125+\langle 80,8\rangle * 0.125+\langle 82,4\rangle * 0.125+\langle 87\rangle * 0.125+$ $\langle 90\rangle * 0.125+<83,2\rangle * 0.125+<83,4\rangle * 0.125$

Skor rata-rata yang dihasilkan adalah 82,775 , sedangkan nilai optimal untuk sebuah perangkat lunak yang memenuhi standar kualitas berdasarkan uji SQA adalah 80 . 
Perencanaan kebutuhan bahan (Material Requirement Planning) pada penelitian ini yaitu untuk menentukan bahan-bahan atau komponen-komponen apa yang harus di buat atau di beli dan berapa jumlah yang dibutuhkan. Material Requirement Planning (MRP) pada dasarnya bertujuan untuk merancang suatu sistem yang mampu menghasilkan informasi untuk mendukung aksi yang tepat baik berupa pengendalian jumlah bahan baku dalam produksi dan data histori pesanan dan data customer.

Hasil dari perhitungan Material Requirement Planning menggunakan aplikasi POM-QM. bahwa pada kolom pd 0 and before atau bahan yang sudah ada di gudang yaitu sebanyak 540 untuk kayu peti, 28500 untuk bahan paku dan 270 untuk log kayu. Untuk kolom selanjutnya pada pd1,pd2,pd3 dan pd4 itu adalah target penyelesaian produk perminggu nya melihat dari data yang di dapat sebagai contoh, pada pd1 target penyelesaian produk sebanyak 2000 kotak di kurangi on hand atau stok yang ada di gudang, maka sisa yang harus di sediakan sebanyak 1460 kotak pada pd1, pd2 sebanyak 5540 kotak, pd3 sebanyak 3540 kotak dan pd4 sebanyak 1540 kotak yang harus di siapkan. Sistem yang di buat pada penelitian ini yaitu dengan menghitung berapa jumlah bahan baku yang harus di sediakan dengan mengacu pada jumlah pesanan perbulan.

Untuk menghitung pembelian bahan baku untuk sebulan atau perbulan nya yaitu menambahkan total pesanan di kurangi stok yang ada. Maka hasil dari total pesanan pada bulan januari sebanyak 12000 kotak persediaan bahan baku 395220 untuk paku dan 11460 untuk Log kayu.

\section{KESIMPULAN}

Dalam penggunaan metode MRP terbukti dapat di terapkan dalam pengendalian jumlah bahan baku, dengan menggunakan metode MRP ini sesuai dengan output yang di harapkan, dapat mempermudah dalam melakukan perhitungan jumlah bahan baku yang di butuhkan. Hasil dari perhitungan jumlah persediaan bahan baku pada bulan januari 2016 terhitung sesuai dengan jumlah pesanan dan dengan di buatkannya sistem untuk mendukung produksi sangat membantu perusahaan dalam mengatur jumlah bahan baku yang harus di siapkan atau di beli. Pada uji aplikasi menggunakan Software Quality Asurance (SQA), dan skor rata-rata yang dihasilkan adalah 82,775, sedangkan nilai optimal untuk sebuah perangkat lunak yang memenuhi standar kualitas berdasarkan uji SQA adalah 80. Maka dapat di simpulkan bahwa aplikasi yang dibuat pada penelitian ini memenuhi standar kualitas SQA.

\section{DAFTAR PUSTAKA}

[1] Zaenal, S. Wijaya, "Penerapan Sistem Informasi Berbasis Komputer Pada Aplikasi Monitoring Keuangan Dan Aset (Terkait Penatausahaan Piutang Tuntutan Ganti Kerugian Negara)", Jurnal Magister Akuntansi jeam.vol. xiv, Surakarta : September 2015.

[2] N. Winarsih, O. Yogi, Y. Vipriyanti,. A. Dewi R dan S. Remi "Penerapan Software Pom-Qm Dalam Pengadaan Material Proyek Dengan Teknik Ppb" Universitas Gunadarma Proceeding PESAT (Psikologi, Ekonomi, Sastra, Arsitektur \& Teknik Sipil) Vol. 5, 8-9, ISSN: 18582559, Bandung : Oktober 2013.

[3] Fachrurrozi dan A. Indra. "Lot Sizing Material Requirement Planning Pada Produk Tipe Wall Mounting Di Industri Box Panel", Jurnal PASTI Volume X No. 3, 279 - 293, Universitas Mercu Buana, Jakarta: 2014.

[4] A. Muhammad. Supriyadi, D. Cahyadi. "Analisis Perencanaan Persediaan Batubara FX dengan Metode Material Requirement Planning” universitas serang raya, Serang: Desember 2017.

[5] Wahyuni. A, S. Achmad. "Perencanaan Persediaan Bahan Baku dengan Menggunakan Metode Material Requirement Planning (MRP) Produk Kacang Shanghai Pada Perusahaan Gangsar 
Ngunut-Tulungagung", Jurusan Teknik Industri STT POMOSDA Nganjuk, Spektrum Industri, Vol. 13, No. 2, 115 - 228, ISSN : 1963-6590, Jawa Timur: 2015.

[6] R. Vella. "Aplikasi Pengendalian Persediaan Bahan Baku Berbasis Web Menggunakan Metode Material Requirement Planning (MRP)",Universitas Telkom, Bandung: 2017.

[7] Y. Muchsam,Falahah, I. Galih Saputro, "Penerapan Gap Analysis Pada Pengembangan Sistem Pendukung Keputusan Penilaian Kinerja Karyawan (Studi Kasus PT.XYZ)" Prodi Teknik Informatika, Universitas Widyatama Bandung Seminar Nasional Aplikasi Teknologi Informasi 2011 (SNATI 2011) ISSN: 1907-5022 Yogyakarta: 17-18 Juni 2011.

[8] Kho,Budi.2016.“Pengertian MRP (Material Requirement Planning) dan tujuan penerapan”, https://ilmu manajemen industri.com/pengertian-MRP-material-requirement-planning-tujuan penerapannya/, di akses pada tanggal 3 July 2016. 